\title{
WEB DESAIN SISTEM PENGELOLAAN DATA MAHASISWA PROGRAM STUDI TEKNIK INFORMATIKA FAKULTAS SAINS DAN TEKNOLOGI UIN SYARIF HIDAYATULLAH JAKARTA
}

\author{
Icheberlyanti1, Viva Arifin2 \\ Mahasiswal, Dosen2 \\ Fakultas Sains dan Teknologi \\ Universitas Islam Negeri Syarif Hidayatullah Jakarta
}

\begin{abstract}
Abstrak
Program Studi Teknik Informatika Fakultas Sains dan Teknologi UIN Syarif Hidayatullah Jakarta, memiliki rata-rata mahasiswa sebanyak 400 an, sejak tahun 2000 sampai dengan tahun 2010. Dalam urusan administrasi, prodi ikut berperan dalam melakukan pencatatan hingga pengolahan pendataan mahasiswa. Kekurangan Sumber Daya Manusia dan pencatatan yang manual menyebabkan lambatnya prodi dalam berkinerja, sehingga terjadilah penumpukan pendataan dan sulitnya mencari informasi mahasiswa secepatnya. Dalam mengatasi hal tersebut, maka perlu dibuat sistem pengelolaan pendataan mahasiswa berbasis web, dengan harapan sistem tersebut dapat meringankan dan mempermudah pegawai dalam hal mengelola data mahasiswa sehingga dapat efektif dan efisien.
\end{abstract}

Keywords : pencatatan manual, system pengelolaan pendataan mahasiswa, web desain

\section{PENDAHULUAN \\ Latar Belakang}

Banyaknya pekerjaan dan

membutuhkan ketelitian dengan pegawai yang terbatas serta waktu deadline yang telah ditentukan. Sebagai salah satu contoh kasus di Program Studi Teknik Informatika Fakultas Sains dan Teknologi UIN Syarif Hidayatullah Jakarta, Prodi tersebut memiliki banyak mahasiswa yang setiap tahunnya ada mahasiswa yang masuk dan keluar (lulus), segala keperluan mahasiswa yang berkaitan dengan kegiatan belajar mengajar (mencatat data pribadi mahasiswa, mencatat nilai mahasiswa, mencatat daftar kelulusan mahasiswa, mencatat judul skripsi dan laporan praktek kerja lapangan) diatur oleh bagian prodi teknik informatika. Setiap akhir semester, mahasiswa juga mendapatkan laporan atau transkip nilai dari hasil kegiatan belajar selama satu semester.

Permasalahannya adalah bagaimana dapat menyelesaikan semua pekerjaan tersebut tepat pada waktunya. Cara bekerja yang masih manual dan terbatasnya jumlah pegawai, maka untuk dapat menyelesaikan semua pekerjaan tersebut membutuhkan tenaga dan waktu yang banyak.

Oleh karena itu, untuk meringankan atau mempermudah dalam mengelola data dibutuhkan sitem basis data yang bersifat otomatis. Dengan adanya system basis data tersebut diharapkan dapat mempermudah pegawai dalam hal mengelola data mahasiswa dengan mudah, efektif dan efisien.

\section{LANDASAN TEORI GAMBARAN UMUM}

\subsection{Website}

World Wide Web (WWW) atau yang biasa disebut dengan Web merupakan salah satu sumber daya internet yang berkembang pesat. Saat ini, informasi web didistribusikan melalui pendekatan hyperlink, yang memungkinkan suatu teks, gambar, ataupun objek yang lain yang menjadi acuan untuk membuka halamanhalaman web yang lain. Dengan pendekatan hyperlink ini, seseorang dapat memperoleh informasi dengan meloncat dari satu halaman ke halaman lain. Halaman-halaman yang diaksespun dapat tersebar di berbagai mesin dan bahkan di beberapa Negara (Kadir, 2005).

\subsubsection{Konsep Dasar Web}

Konsep yang mendasari aplikasi Web sebenarnya sederhana. Operasi yang melatarbelakanginya melibatkan pertukaran informasi antara komputer yang meminta informasi, yang disebut client, dan komputer yang memasok informasi (atau disebut server). Secara lebih detail, server 
yang melayani permintaan dari client sesungguhnya berupa suatu perangkat lunak yang disebut Web server. Secara internal, Web server inilah yang berkomunikasi dengan perangkat lunak lain atau middleware dan middleware inilah yang berhubungan dengan database (Kadir, 2005).

\subsubsection{Dasar-dasar Desain Website}

Dasar-dasar desain website adalah aturanaturan yang ditujukan guna memperindah suatu desain website agar dapat menarik perhatian para pengguna dan juga memberikan kenyamanan kepada pengguna sewaktu melihat tampilan website. Aturanaturan tersebut seperti kontras, repetisi, alignment dan juga kedekatan (proximity) (Bakawan, 2007).

\subsubsection{Prinsip-prinsip Desain Website}

Prinsip-prinsip desain website adalah kaidah-kaidah desain yang dibuat dengan tujuan agar website yang dibuat selain dapat memberikan informasi terhadap pengguna juga dapat memenuhi nilai-nilai keindahan serta kenyamanan. Berikut prinsip-prinsip desain website yang penulis gunakan sebagai acuan pembuatan website antara lain, guilding the eye, space, navigation, typography, usability, alignment, clarity (sharpness), consistency (Ridha, 2008).

\subsection{Pengelolaan Data}

\subsubsection{Tujuan Pengelolaan Data}

Tujuan pengolahan data adalah untuk menghasilkan dan memelihara data perusahaan yang akurat dan up to date.

\subsubsection{Tugas Pengelolaan Data}

Tanpa memandang apakah system pengolahan data perupa manual, key driven computer atau kombinasi ada empat tugas dasar yang dilakukan : Pengumpulan data, Pengubahan data, Penyimpanan data, dan Pembuatan dokumen

\subsection{Tool - Tool Yang Digunakan}

\subsubsection{PHP (Personal Home Page)} PHP (Hypertext Preprocessor) dikembangkan pertama kali tahun 1995 oleh Rasmus Lerdorf yang merupakan salah satu anggota group Apache. PHP pertama kali didesain sebagai alat tracking pengunjung web site Lerdorf. Kemudian, fungsinya diperlebar dan dihubungkan dengan Apache. PHP dikembangkan sepenuhnya untuk bahasa skrip side-server programming. PHP bersifat open-source dan dapat digabungkan dengan berbagai server yang berbeda-beda. PHP mempunyai kemampuan dapat mengakses database dan diintegrasikan dengan HTML. Berdasarkan hasil survei yang dilakukan Netcraft (http://www.netcraft.com), PHP lebih popular dalam jumlah pemakai dibanding dengan modul perl, CGI, dan ASP.

PHP adalah bahasa server-side programming yang power full untuk membuat halaman web yang dinamis dan interaktif. Sintak PHP mirip dengan bahasa Perl dan C. PHP biasanya sering digunakan bersama web server Apache di beragam sistem operasi. PHP juga men-support ISAPI dan dapat digunakan bersama dengan Microsoft IIS di Windows.

PHP merupakan software open source, dapat digunakan dengan gratis dan dapat dijadikan alternatif selain side-server programming yang lain (Microsoft ASP). Sintak PHP dapat dituliskan langsung di antara kode HTML (Sunyoto, 2007:119).

\subsubsection{MYSQL}

MySQL merupakan database yang sangat terkenal di kalangan programmer web karena MySQL merupakan database yang stabil dalam penyimpanan data. Begitu banyak programmer, baik programmer web atau programmer aplikasi database yang menggunakan MySQL sebagai media untuk penyimpanan data. MySQL mampu menangani data yang cukup besar yaitu sekitar 40 database dan 10.000 tabel serta jutaan baris yang bisa ditampung oleh MySQL.

Selain kemampuan dalam penyimpanan data yang stabil, MySQL juga telah mendukung Relasional Database Manajemen Sistem (RDBMS). MySQL merupakan software database yang sifatnya gratis artinya Anda tidak dikenakan biaya. Untuk mendapatkan MySQL ini Anda bisa langsung download dari situsnya yaitu: www.mysql.com (Ibrahim, 2008: 67).

\subsubsection{Koneksi PHP ke MYSQL}

Untuk melakukan koneksi dengan MySQL, PHP telah menyediakan berbagai macam fungsi untuk keperluan 
tersebut.Fungsi - fungsi tersebut adalah :

1. Mysql_connect()

Fungsi ini digunakan untuk membuka koneksi ke MySQL. Sintaksnya sebagai berikut: \$conn = Mysql_connect ( host , user, password )

2. Mysql_select_db()

Fungsi ini digunakan untuk memilih database yang akan digunakan. Sintaksnya sebagai berikut : Mysql_select_db (namadatabase [,koneksi] )

3. Mysql_query()

Fungsi ini digunakan untuk mengambil sebuah query dari sebuah database. Sintaksnya sebagai berikut : \$qry = Mysql_query ( perintah sql [,koneksi] )

4. Mysql_fetch_array()

Fungsi ini digunakan untuk mengambil record dari database dan dimasukkannya ke dalam array asosiatif , array numeris, atau keduanya. Sintaksnya sebagai berikut : \$row = Mysql_fetch_array ( \$qry )

5. Mysql_fetch_assoc()

Fungsi ini hampir sama dengan mysql_fetch_array(), hanya saja array yang dihasilkan hanya array asosiatif. Sintaksny sebagai berikut : \$row = Mysql_fetch_assoc ( \$qry )

6. Mysql_fetch_row()

Fungsi ini hampir sama dengan mysql_fetch_array(), hanya saja array yang dihasilkan hanya array numeris. Sintaksny sebagai berikut : \$row = Mysql_fetch_row ( \$qry )

7. Mysql_num_fields()

Fungsi ini digunakan untuk menghitung jumlah field yang ada pada database. Sintaksnya sebagai berikut : $\$ \mathrm{jml}=$ Mysql_num_fields( \$qry)

8. Mysql_num_rows()

Fungsi ini digunakan untuk menghitung jumlah record yang ada pada database. Sintaksnya sebagai berikut : $\$ \mathrm{jml}=$ Mysql_num_rows( \$qry )

9. Mysql_close()

Fungsi ini digunakan untuk menutup koneksi yang telah dilakukan. Sintaksnya sebagai berikut : Mysql_close ( [ koneksi ] )

10. Mysql_pconnect()

Fungsi ini memiliki kegunaan yang sama dengan mysql_connect(), hanya saja koneksi yang dibuka bersifat persiten. Sintaksnya sebagai berikut : \$pconn = Mysql_pconnect ( host , user , password )

11. Mysql_create_db()

Untuk kasus dimana Anda tidak dapat mengakses MySQL secara langsung maka anda memerlukan fungsi mysql_create_db(). Sintaksnya sebagai berikut

Mysql_create_db(namadatabase)

\subsubsection{XAMPP}

XAMPP adalah perangkat lunak gratis, yang mendukung banyak sistem operasi, merupakan kompilasi dari beberapa program. Fungsinya adalah sebagai server yang berdiri sendiri (localhost), yang terdiri atas program Apache HTTP Server, MySQL database, dan penterjemah bahasa yang ditulis dengan bahasa pemrograman PHP dan Perl. Nama XAMPP merupakan singkatan dari $\mathrm{X}$ (empat system operasi apapun), Apache, MySQL, PHP dan Perl. Program ini tersedia dalam GNU General Public Lisensi dan bebas, merupakan web server yang mudah digunakan yang dapat melayani tampilan halaman web yang dinamis. Untuk mendapatkanya dapat mendownload langsung dari web resminya. (Ibrahim, 2008: 3).

\subsubsection{Adobe photoshop 7.0}

Adobe Photoshop 7.0 adalah salah satu program pengolah image (image processor) untuk gambar bitmap dari Adobe Systems Incorporated. Sebagai salah satu program aplikasi yang cukup powerfull, Adobe Photoshop 7 telah banyak digunakan oleh para professional untuk membuat dan memanipulasi gambar, baik untuk keperluan media percetakan, internet maupun elektronik. Keunggulan dan kekuatan Adobe Photoshop 7.0 terletak antara lain pada kemudahan, fasilitas, dan fleksibilitasnya (Hakim, 2002).

\subsubsection{Macromedia Dreamweaver 8}

Macromedia Dreamweaver 8 merupakan aplikasi desain web visual yang biasa dikenal dengan istilah What You See Is What You Get (WYSIWYG), intinya Anda tidak secara langsung harus berurusan dengan tag-tag HTML untuk membuat sebuah situs.

Aplikasi ini dipilih karena 
kemudahannya dalam mendesain halaman web dengan fasilitas intellisense sehingga pada saat mengetikkan beberapa huruf kode maka akan tampil secara otomatis semua properti yang ada dalam tag. Kemampuannya dalam mengenali beberapa kode pemrograman dan skrip seperti HTML, PHP, ASP, VBSript, CSS, JavaScript, XML, dan lain-lainnya menjadikannya lebih powerfull.

Dreamweaver merupakan sebuah editor HTML profesional untuk mendesain secara visual dan mengelola situs web beserta halaman web. Sekarang ini sangat banyak sekali programmer menggunakan editor dreamweaver karena begitu banyak fasilitas yang disediakan (Ibrahim, 2008: 27).

\section{METODOLOGI PENELITIAN}

3.1. Metode Pegumpulan Data

a) Observasi

Peneliti mengumpulkan data dan informasi dengan cara meninjau dan mengamati secara langsung kegiatan di lapangan, yaitu di Program Studi Teknik Informatika.

b) Wawancara

Peneliti melakukan wawancara kepada pihak-pihak terkait yang akan menggunakan system tersebut.

c) Studi Pustaka

Peneliti membaca dan mempelajari buku-buku referensi yang berkaitan dengan penelitian ini.

\subsection{Metode Pengembangan Sistem}

Metode pengembangan sistem yang digunakan yaitu metode System Developement Life Cycle (SDLC). Langkahlangkah yang dilakukan penulis dalam tahapan pengembangan sistem dengan metode ini sebagai berikut:

a) Analisis (Analysis)

Tahap ini berisi uraian sistem saat ini dan analisis sistem saat ini serta menganalisa kebutuhan sistem. Uraian sistem saat ini merupakan gambaran secara detail sistem saat ini dengan masalah-masalah yang dimilikinya.

Analisis sistem saat ini merupakan proses memahami masalah-masalah yang ada. Hasilnya berupa usulanusulan guna merancang sistem baru yang dapat mengatasi permasalahan yang ada. Tahap ini meliputi :

1) Uraian Sistem Saat ini

Kegiatan menguraikan sistem yang sedang berjalan pada saat ini di Program Studi Teknik Informatika

2) Analisa Sistem Saat ini

Menganalisa uraian sistem yang sedang berjalan dan kebutuhan sistem yang akan dibangun.

b) Perancangan (Design)

Adapun langkah-langkah yang dilakukan pada tahap ini, yaitu pembuatan struktur navigasi, perancangan proses, perancangan arsitektur, perancangan halaman, perancangan database, pemrograman web, dan tampilan website

c) Pengkodean (coding)

Pada tahap ini berisi implementasi ke dalam bahasa pemrograman. Bahasa pemrograman yang digunakan menggunakan PHP dan perangakat lunak Sistem Manajemen Basis Data menggunakan MySQL.

d) Pengujian (Testing)

Pengujian sistem baru akan menggunakan pendekatan Black Box dengan metode Unit Test dan Integration Test. Pada pengujian Unit Test, peneliti melakukan pengujian masing-masing komponen program untuk meyakinkan bahwa sudah beroperasi dengan benar. Sedangkan pada pengujian Integration Test, peneliti melakukan pengujian kelompok komponen-komponen yang terintegrasi untuk membentuk sub-sistem.

e) Penerapan (Acceptance)

Dalam tahap ini dilakukan strategi penerapan system yaitu pelatihan. Selanjutnya adalah Go Live, yaitu penerapan system tersebut di prodi

f) Perawatan (Maintenance)

Perawatan dan pemantauan system akan dilakukan oleh staff akademik apakah di prodi atau fakultas

\section{HASIL DAN PEMBAHASAN MASALAH}

Untuk membuat situs web kita dikunjungi oleh banyak pengunjung, kita harus memperhatikan isi dan struktur dari situs web kita. Karena internet media 
informasi yang murah.

Maksud dan tujuan pembuatan suatu website yaitu menampilkan informasiinformasi yang dimiliki pada pembuatan website tersebut, dalam hal ini adalah pembuatan website Program Studi Teknik Informatika.

\subsection{Struktur Navigasi}

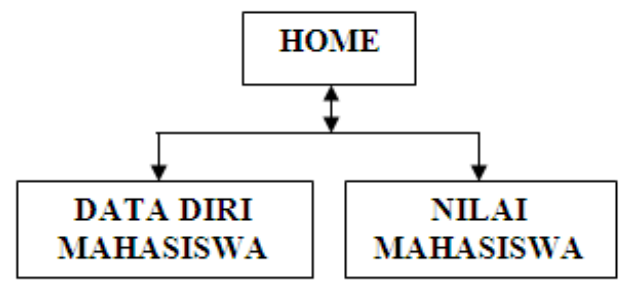

4.2 Spesifikasi Proses

4.2.1 Spesifikasi proses data mahasiswa

\begin{tabular}{|l|l|}
\hline Nama Proses & $\begin{array}{l}\text { Input / ubah data } \\
\text { mahasiswa }\end{array}$ \\
\hline Deskripsi & $\begin{array}{l}\text { Menambahkan / merubah } \\
\text { data mahasiswa }\end{array}$ \\
\hline Input & $\begin{array}{l}\text { Nim,Nama, Tanggal Lahir, } \\
\text { Alamat, Telepon, Email }\end{array}$ \\
\hline Output & Data mahsiswa \\
\hline Logika proses & $\begin{array}{l}\text { 1.Admin memilih menu } \\
\text { tmabah atau ubah data } \\
\text { mahasiswa } \\
\text { 2.Admin melakukan input } \\
\text { atau ubah data mahasiswa } \\
\text { 3. Klik proses jika semua } \\
\text { kolom sudah terisi } \\
\text { 4. Jika mahasiswa } \\
\text { melaukan perubahan } \\
\text { password, maka system } \\
\text { akan melakukan } \\
\text { sinkronisasi dengan } \\
\text { database. }\end{array}$ \\
\hline
\end{tabular}

4.2.2 Spesifikasi Proses nilai mahasiswa

\begin{tabular}{|l|l|}
\hline Nama Proses & Input / ubah data nilai \\
\hline Deskripsi & $\begin{array}{l}\text { Menambahkan / } \\
\text { merubah data nilai }\end{array}$ \\
\hline Input & $\begin{array}{l}\text { Nim,Nama, Mata } \\
\text { Kuliah, SKS, Nilai, } \\
\text { Huruf }\end{array}$ \\
\hline Output & Data nilai \\
\hline Logika proses & $\begin{array}{l}\text { 1.Admin melakukan } \\
\text { input atau ubah data } \\
\text { nilai }\end{array}$ \\
\hline
\end{tabular}

\begin{tabular}{|l|l|}
\hline & $\begin{array}{l}\text { 2. Klik proses jika } \\
\text { semua kolom sudah } \\
\text { terisi }\end{array}$ \\
\hline
\end{tabular}

4.3 Disain Arsitektur

\subsubsection{Diagram Proses Data Diri Mahasiswa}

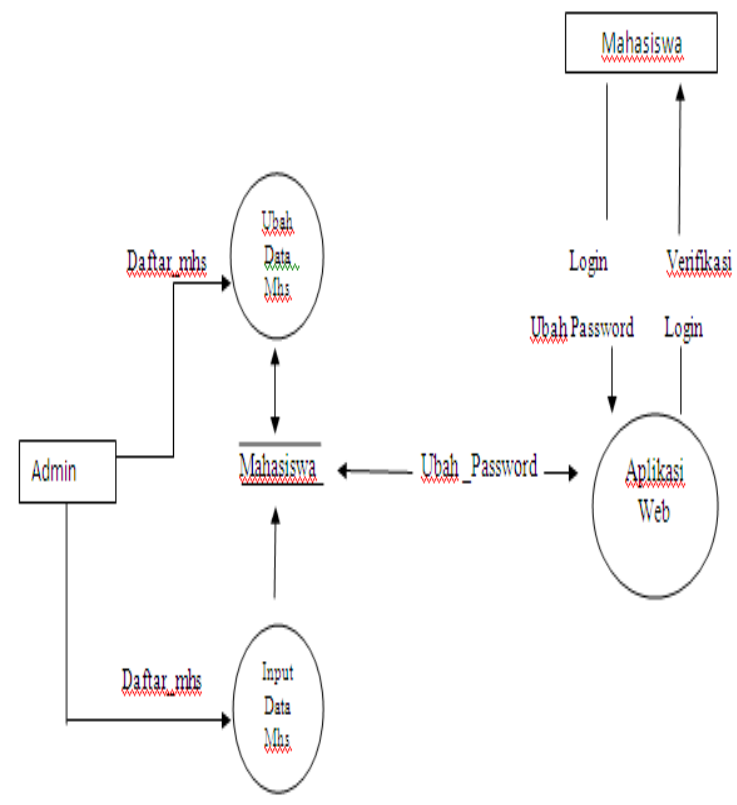

Gambar 4.1. Diagram Proses Data Diri Mahasiswa

Pada proses input / ubah data diri mahasiswa, admin memasukkan data mahasiswa. Dan Mahasiswa hanya dapat mengubah password.

\subsubsection{Diagram Proses Data Nilai}




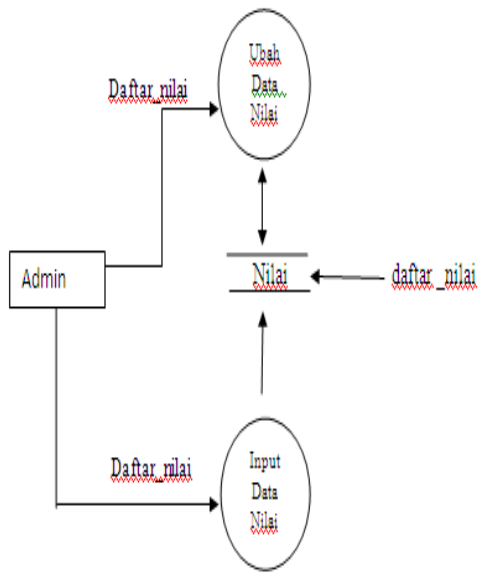

\section{Gambar 4.2. Diagram Proses Data Nilai}

Pada proses input data nilai admin memasukkan data nilai mahasiswa, dan mahasiswa hanya bisa melihat dan mencetak nilai.

\subsection{Rancangan Tiap Halaman Primer}

Website Podi Teknik Informatika ini mempunyai 3 (lima) halaman primer, diantaranya halaman Home, halaman Data Diri Mahasiswa, dan halaman Nilai Mahasiswa.

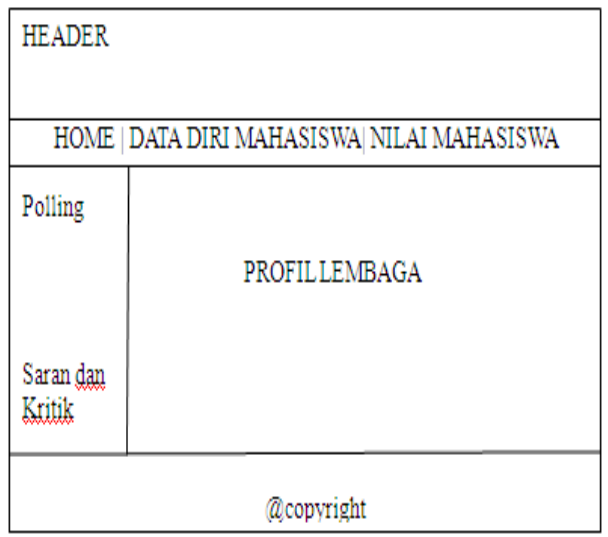

Gambar 4.3. Rancangan Halaman Home

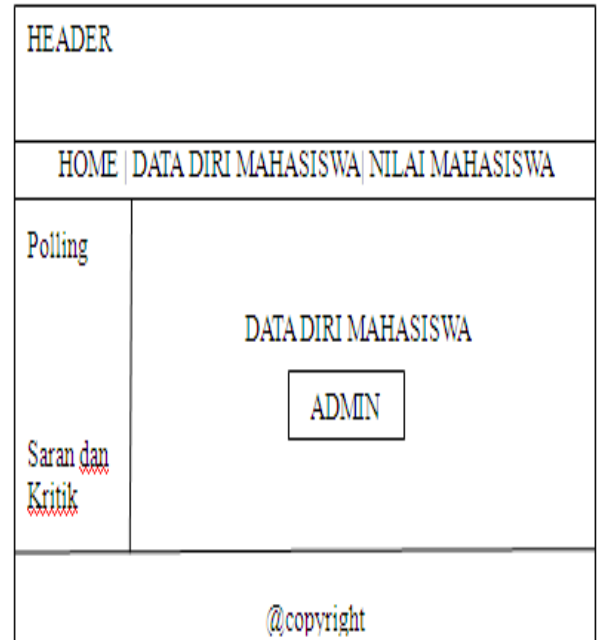

Gambar 4.4. Rancangan Halaman Data Diri Mahasiswa

\begin{tabular}{|l|r|}
\hline HEADER \\
\hline \multicolumn{2}{|c|}{ HOME $\mid$ DATA DIRI MAHASISWA NILAI MAHASISWA } \\
\hline Polling & NILAI MAHASISWA \\
& ADMIN \\
Saran dan & \\
Kritik & MAHASISWA \\
\hline & acopyright \\
\hline
\end{tabular}

Gambar 4.5. Rancangan Halaman Nilai Mahasiswa 


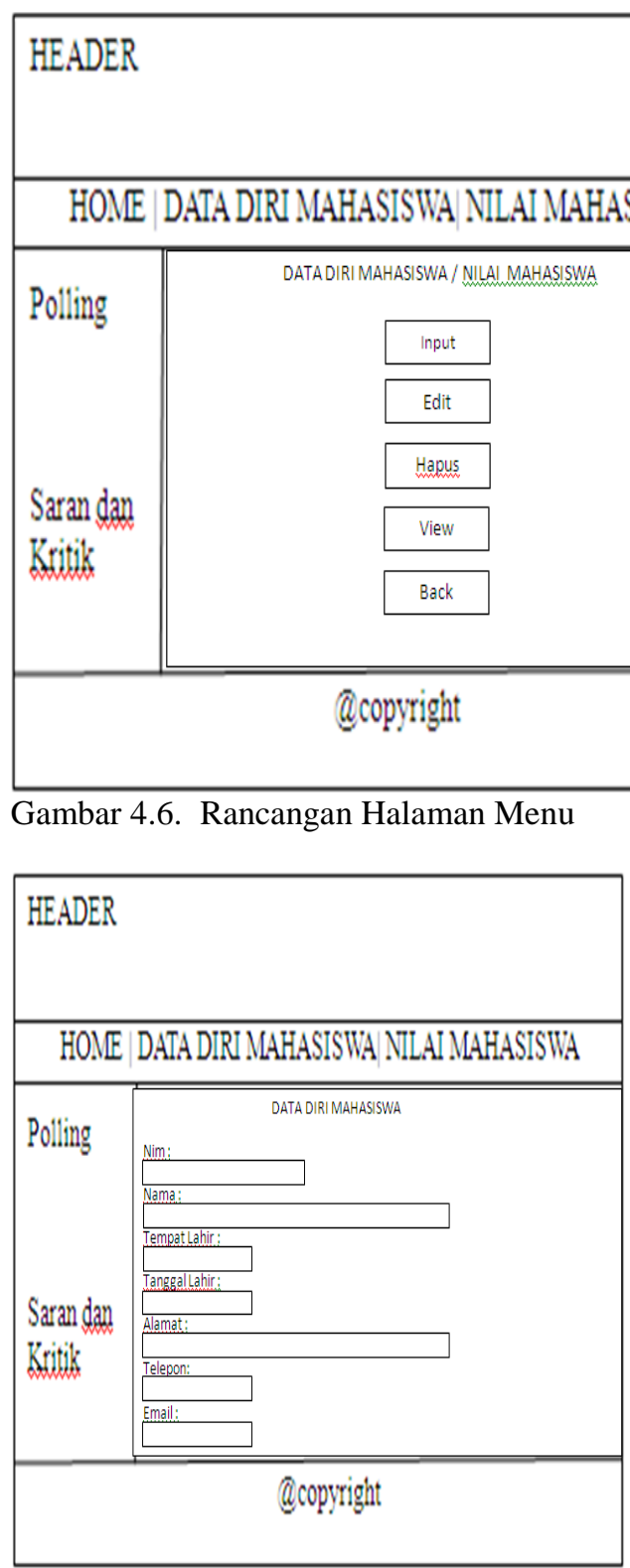

Gambar 4.7. Rancangan Halaman Input Data Diri Mahasiswa
HEADER

HOVE DATA DIRIMAHASSSTIA NZLAIMAHASSITA

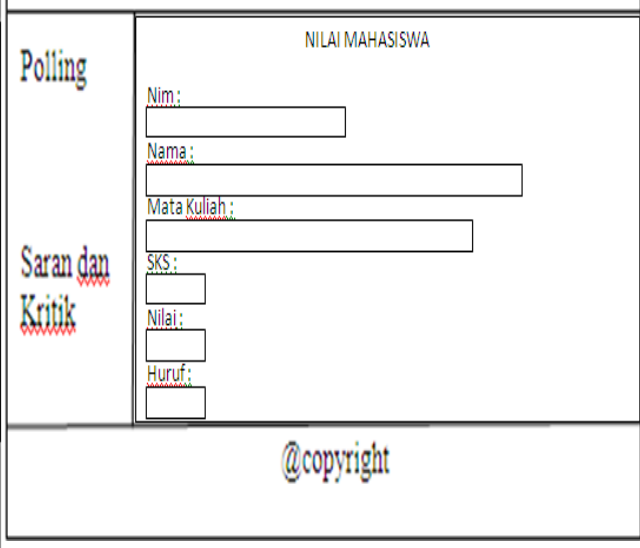

Gambar 4.8. Rancangan Halaman Input Nilai Mahasiswa

\subsection{Rancangan Database}

Sebelum masuk ke tahap pemrograman, peneliti harus mempersiapkan tempat untuk menampung data di server, data tersebut nantinya akan diproses oleh program yang penulis buat pada tahap pemrograman, baik proses penambahan, pengeditan, penghapusan, dan penampilah database ke halaman web.

\subsubsection{Login ke PhpMyAdmin}

PhpMyadmin merupakan suatu tempat pembuatan database pada server database lokal. Langkah-langkahnya adalah hidupkan Apache sebagai web server, dimana ketika program xampp sudah terinstal, urutannya adalah Start $>$ All Programs $>$ Apache Friends $>$ XAMPP $>$ XAMPP Control Panel

\subsubsection{Membuat Tabel Database}

1. Ketika Web Server dan Database Server sudah dihidupkan ketikkan pada Web Browser alamat http://localhost /phpmyadmin

2. Ketikkan pada kolom yang terletak di bawah Create new database sebuah nama database nya, lalu tekan tombol create.

Setelah pembuatan database prodi selesai, tahap berikutnya adalah pembuatan tabel, klik database prodi, lalu masukkan nama tabel saran, data_mhs, nilai_mhs dan jumlah fieldnya 


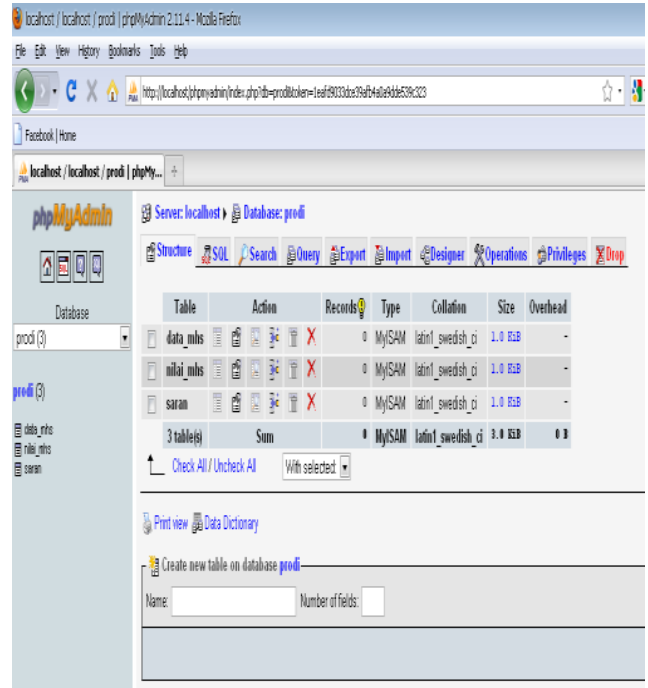

Gambar 4.13. Membuat Database Tabel saran, data_mhs, nilai_mhs

Masukkan nama field dan tipe data sesuai dengan fieldnya

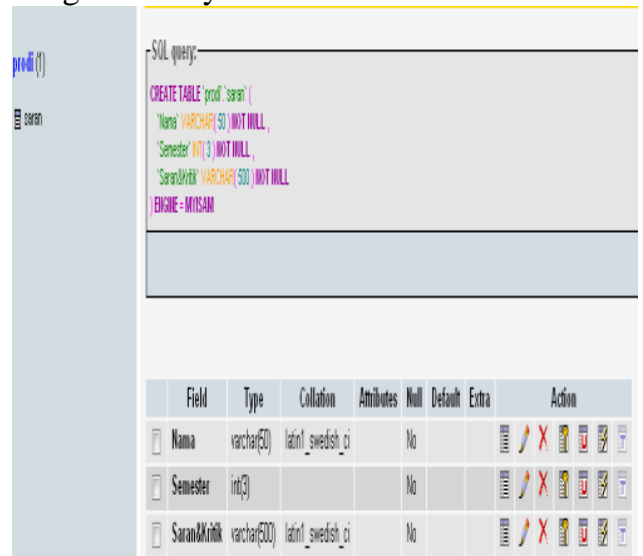

Gambar 4.14. Database Tabel Prodi Saran

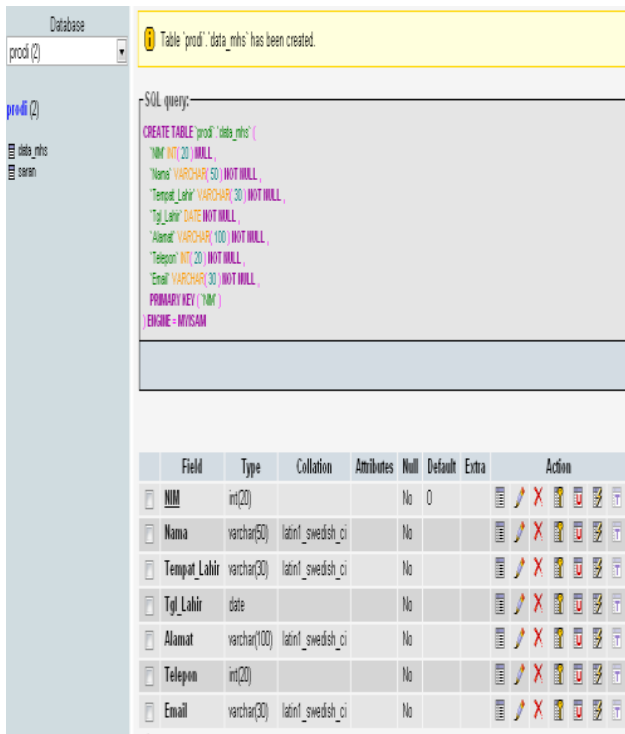

Gambar 4.15. Database Tabel prodi data_mhs

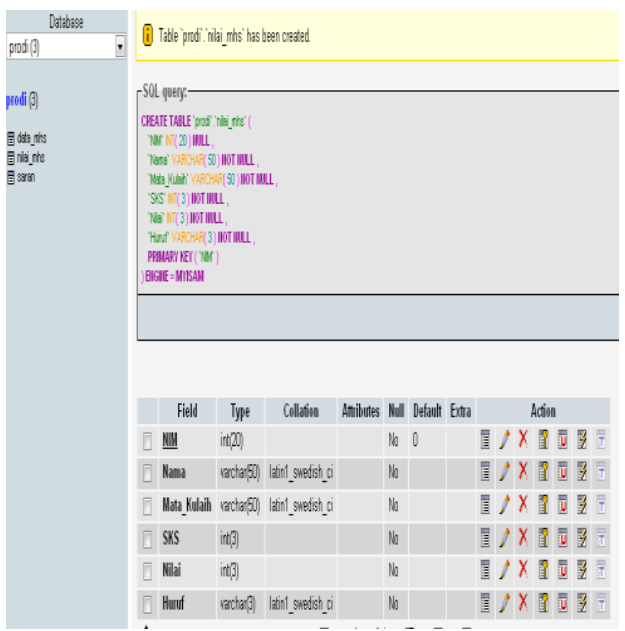

Gambar 4.16. Database Tabel prodi nilai_mhs

\subsection{Pemrograman Web}

Pada bagian pemrograman, di dalamnya ada beberapa tahap dalam membuatnya utuh menjadi satu kesatuan. Tahap Pertama yang harus diperhatikan ialah koneksi program yang penulis buat ke dalam database server lokal. Sebagai simulasi pada web yang dibuat peneliti.

\subsubsection{Mengakses Koneksi Database}

Sebelum melakukan tahap pemrograman yang nantinya akan banyak berurusan dengan menuliskan kode-kode berbentuk skrip dan juga akan sering berhubungan atau koneksi ke database, maka sebaiknya buatlah terlebih dahulu skrip yang akan berguna sebagai konektor dari skrip-skrip 
aplikasi yang peneliti buat.

\subsection{Disain Interface Website}

Setelah selesai merancang navigasi, halaman, dan database website, maka tahap selanjutnya yang peneliti lakukan adalah mendisain interface website. Pada tahap ini, peneliti membuat desain untuk grafik yang akan ditampilkan di halaman web nantinya. Di sini peneliti berperan sekaligus menjadi web designer.

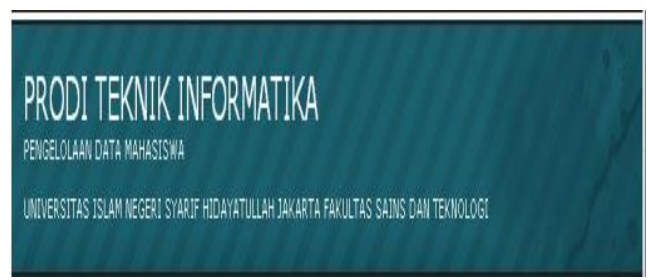

Gambar 4.17. Disain Header Website

\subsection{Penggabungan Disain dan Pemrograman Web}

Tahap berikutnya adalah menyatukan semua desain dan pemrograman, sehingga menjadi satu kesatuan halaman web yang utuh. Dalam melakukan penggabungan ini dilakukan beberapa tahap yang akan dijelaskan juga oleh pihak peneliti, beberapa tahap tersebut adalah :

\section{Mengatur tempat penyimpanan file di dalam server local}

Sebelum melakukan penggabungan ada hal penting yang harus diperhatikan yaitu mengatur tempat penyimpanan file yang penulis butuhkan, karena selama melakukan disain dan pemrograman, file-file nya di tempat atau di folder yang berbeda, maka penulis atur terlebih dahulu dalam satu folder.

\section{Mengorganisasikan File Web}

Sebelum penulis membuat halamanhalaman web, penulis perlu membuat suatu tempat untuk menampung file-file web tersebut. Hal ini dimaksudkan untuk memudahkan penulis dalam bekerja, karena penulis akan bekerja dengan banyak file, jadi, seluruh file harus tertata rapi.

\section{Mempersiapkan Halaman Web}

Pertama-tama yang harus dilakukan dalam penggabungan disain dan pemrograman ini adalah mempersiapkan halaman yang akan menampung semua disain dan pemrograman tersebut, disinilah peneliti menentukan jenis halaman web yang akan dibuat.

Setelah melakukan tahapan-tahapan di atas, maka didapatkan hasil layout halaman web yang utuh dan dapat di akses dengan Browser Internet Explorer, di bawah ini tampilan website yang dioperasikan pada server lokal.

\subsection{Tampilan Website}

\subsubsection{Interface Index / Home}
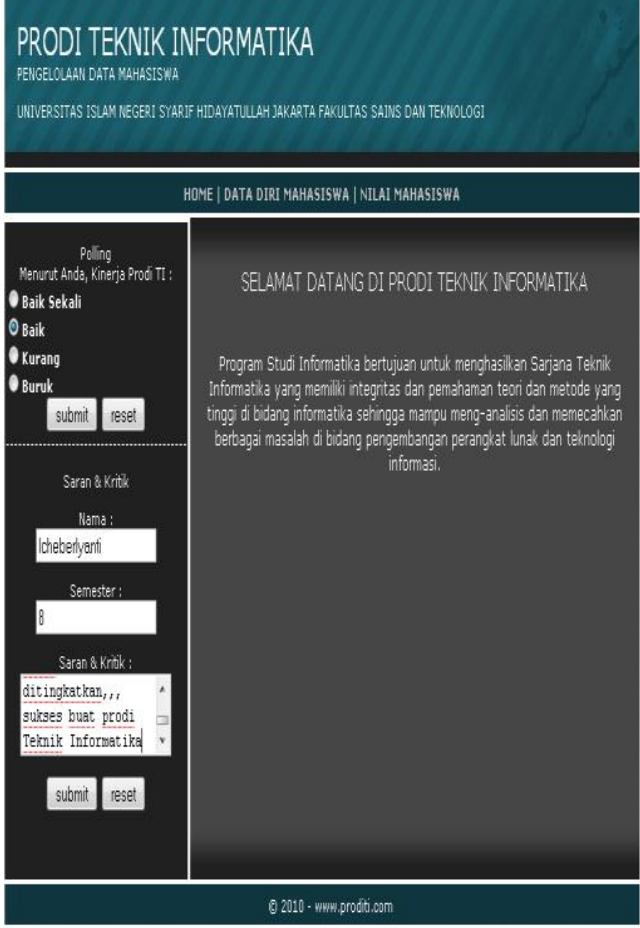

Gambar 4.18. Interface Halaman Home

\subsubsection{Interface Login}

Untuk memasuki halaman menu tama, pertama-tama admin harus melakukan login terlebih dahulu dengan memasukkan username dan password. 


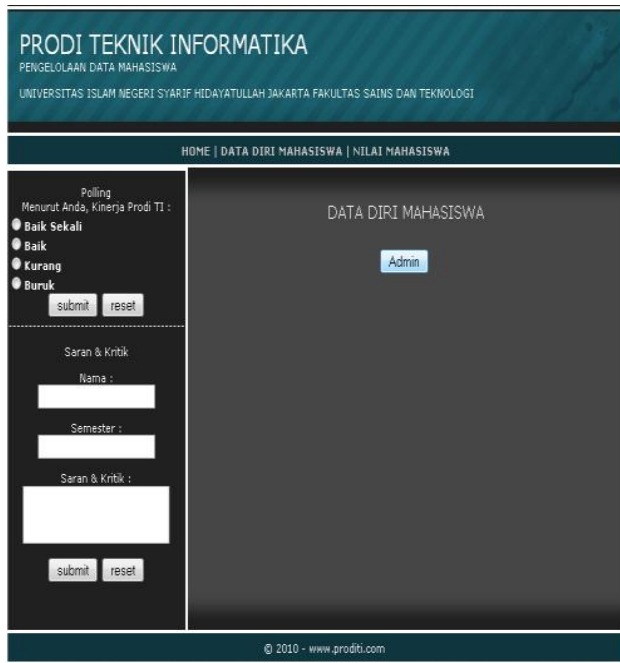

Gambar 4.19. Halaman Admin

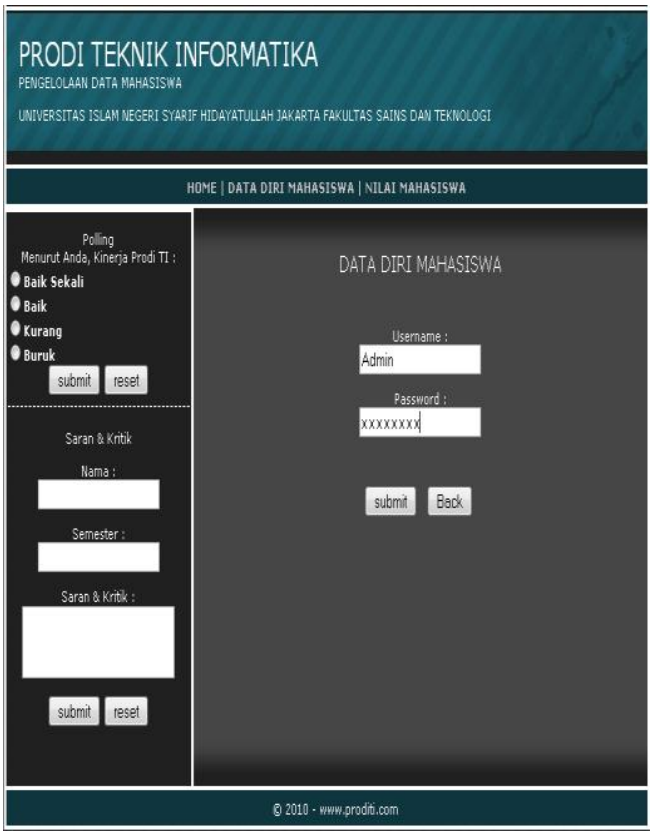

Gambar 4.20. Halaman Login Admin

\subsubsection{Interface Menu Data Diri Mahasiswa}

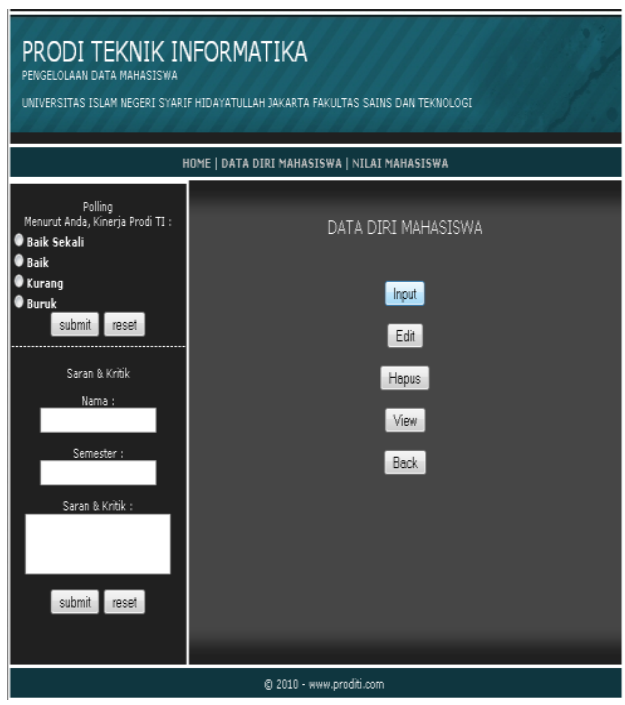

Gambar 4.21. Halaman menu admin

\subsubsection{Interface Menu Input Mahasiswa}

Halaman ini menampilkan form input untuk tambah data mahasiswa.

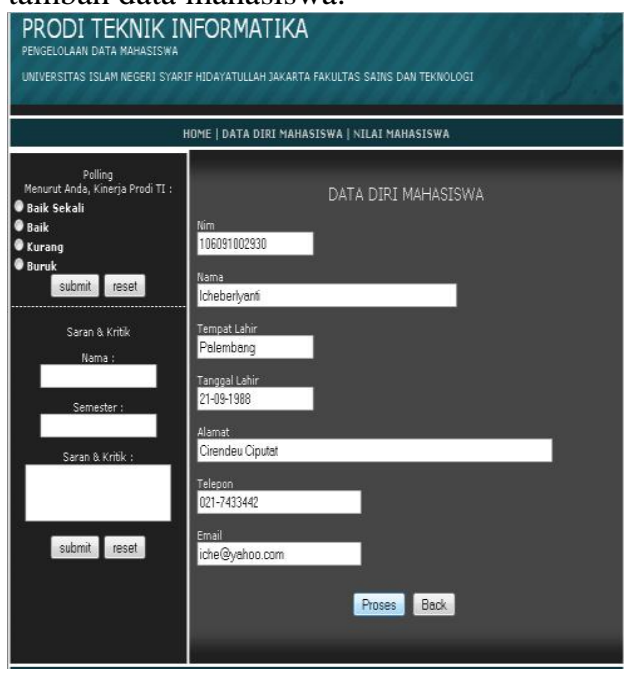

Gambar 4.22. Form Input Data Mahasiswa

4.9.5 Interface View Data Mahasiswa Halaman ini menampilkan semua data mahasiswa yang sudah di input. 


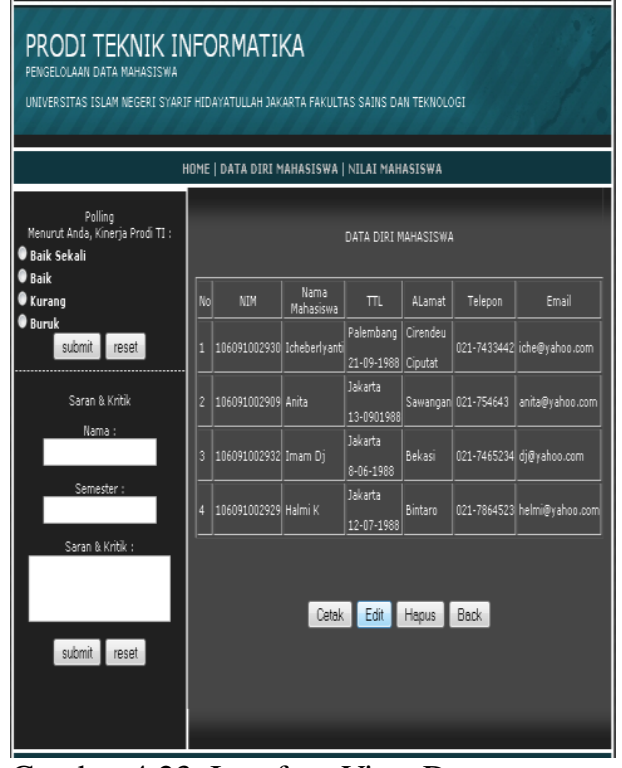

Gambar 4.23. Interface View Data

\subsubsection{Interface search data diri} mahasiswa

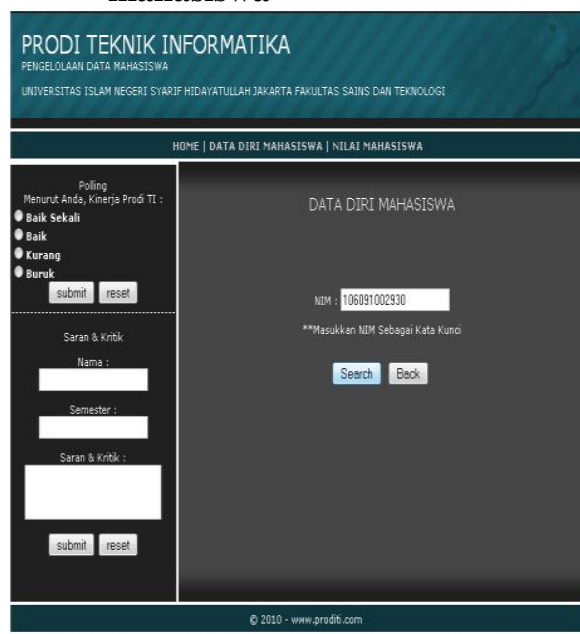

Gambar 4.24. Search Data

4.9.7 Interface menu nilai mahasiswa

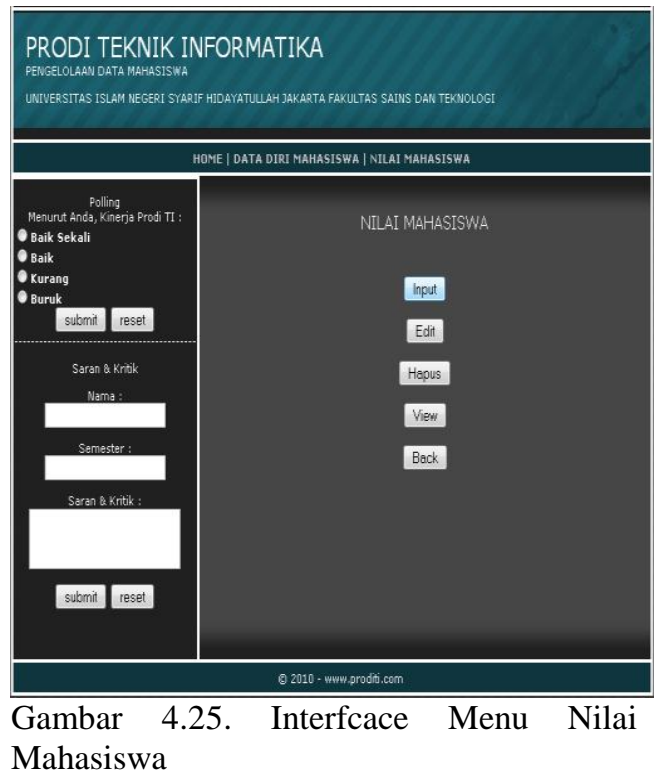

\subsubsection{Interface Input Nilai Mahasiswa}

Halaman ini menampilkan form untuk input nilai mahasiswa.

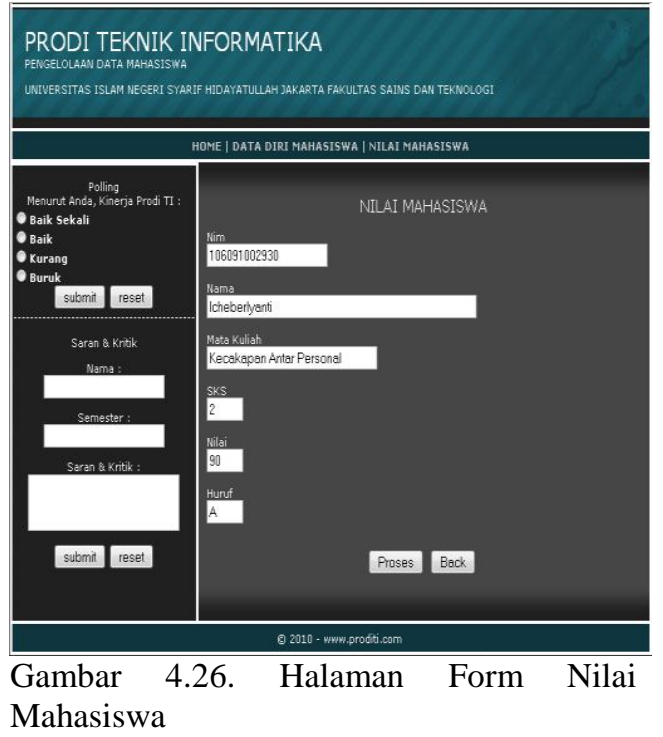

4.9.9 Interface View Nilai Mahasiswa 


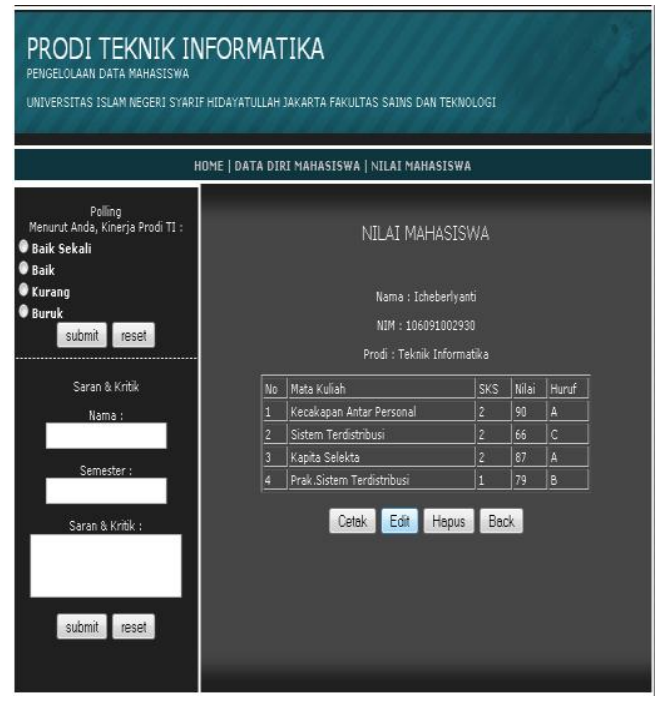

Gambar 4.27. Interface View Nilai

\subsubsection{Interface Login Mahasiswa}

Halaman ini berisikan login mahasiswa untuk dapat melihat nilai mahasiswa.

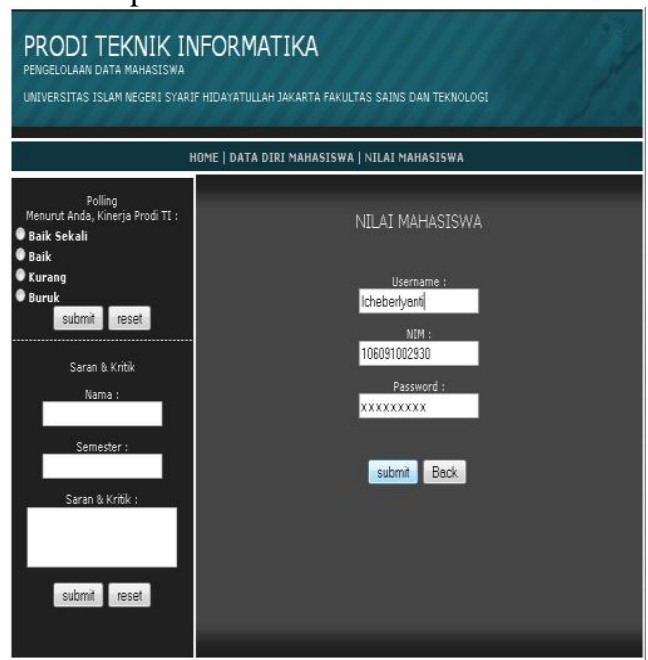

Gambar 4.28. Interface Login Mahasiswa

\subsubsection{Interface View Nilai oleh Mahasiswa}

Halaman berisi nilai dari mahasiswa yang sudah diinput. Mahasiswa bisa langsung mencetak daftar nilai tersebut.

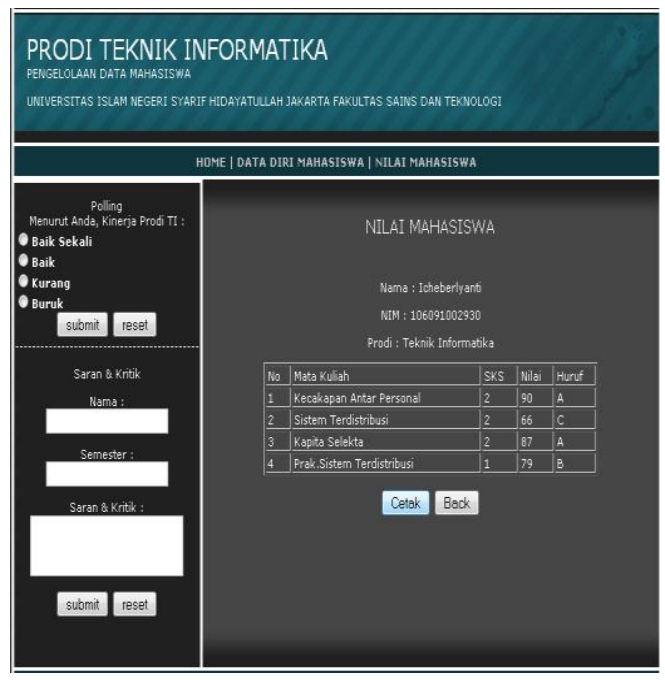

Gambar 4.29. Halaman View Nilai Oleh Mahasiswa

\section{PENUTUP}

\subsection{Kesimpulan}

Setelah merancang desain web dan membuat aplikasi webnya, dapat disimpulkan bahwa :

1. Dengan adanya aplikasi web ini dapat menghemat waktu karena pihak staff prodi tidak dipusingkan dengan masalah mahasiswa yang ingin melihat nilai.

2. Aplikasi ini memudah kan mahasiswa dalam mengakses kebutuhan informasi akademik seperti nilai.

\subsection{Saran}

Berikut ini adalah beberapa saran yang diberikan dan dapat berguna dalam meningkatkan kinerja system yang telah berjalan saat ini, yaitu :

1. Perlu adanya maintenance dan update secara berkala, untuk menambah atau mengganti informasi-informasi yang telah lewat.

2. Aplikasi ini membutuhkan administrator dalam menjalankan sistem informasi agar datanya ter update.

3. Perlunya komputerisasi menyeluruh pada pada seluruh sistem yang berhubungan dengan updatenya informasi yang akan dikirim.

4. Perlunya staff yang benar-benar mengelola data mahasiswa dengan baik sehingga tidak terdapat kekeliruan dalam proses penyimpanan data.

5. Tanpa ada pengawasan dan pemeliharaan pada sistem-sistem yang 
ada maka sistem tidak akan berjalan dengan sebagai mana semestinya.

\section{DAFTAR PUSTAKA}

1. Hakim, Lukmanul. 2008. Membongkar Trik Rahasia Para Master PHP. Yogyakarta: Lokomedia

2. Hakim, Lukmanul. 2009. Trik Rahasia Master PHP Terbongkar Lagi. Yogyakarta: Lokomedia

3. Husni. 2007. Pemrograman Database Berbasis Web. Yogyakarta : Graha Ilmu

4. Ibrahim, Ali. 2008. Cara Praktis Membuat Website Dinamis Menggunakan XAMPP. Yogyakarta: Neotekno

5. Kadir, Abdul. 2006. Pengenalan Sistem
Informasi. Yogyakarta: Andi

6. Kasiman, Peranginangin, 2006.

Aplikasi Web dengan PHP dan $M y S Q L "$, ANDI Yogyakarta,

7. Kurniawan, Yahya , "Aplikasi Web Database dengan PHP dan MySQL", PT. Elex Media Komputindo, Jakarta, 2002.

8. Sidik, Betha, 2002."Pemrograman Web dengan PHP", nformatika, Bandung, Oktober

9. Suprianto, Dodit. 2008. Buku Pintar Pemrograman PHP. Jakarta : Oasemedia

10. Syafii, M, 2002." Panduan Membuat Aplikasi Database dengan PHP”, ANDI Yogyakarta. 